\title{
ЗОВНІШНЯ БАЛІСТИКА СНАРЯДУ БМ1 ВИПУЩЕНОГО 3 Т-12 (МТ-12)
}

\author{
${ }^{1}$ К.ф.м.н. Величко Лев Дмитрович, \\ ${ }^{2}$ Полковник Горчинський Ігор Володимирович, \\ ${ }^{3}$ К. ф.-м.н. Сорокатий Микола Іванович
}

\begin{abstract}
Украӥна, Львів, Національна академія сухопутних військ
імені гетьмана Петра Сагайдачного

${ }^{I}$ Професор кафедри інженерної механіки (озброєння та техніки інженерних військ)

${ }^{2}$ Начальник факультету підготовки спеціалістів бойового (оперативного) забезпечення

${ }^{3}$ Професор кафедри інженерної механіки (озброєння та техніки інженерних військ)
\end{abstract}

DOI: https://doi.org/10.31435/rsglobal_ws/31012020/6891

\begin{abstract}
ARTICLE INFO
Received: 13 November 2019

Accepted: 17 January 2020

Published: 31 January 2020

\section{KEYWORDS}

external ballistics,

T-12 gun,

frontal air resistance force,

firing corrections.

ABSTRACT

The magnitudes of the kinematic parameters of projectiles motion in the air depends on deterministic (form of projectile, its mass, temperature of air and charge, atmospheric pressure, derivation) and nondeterministic (muzzle velocity, magnitude and direction of wind velocity) values. During the projectile movement, its weight and frontal air resistance force have a determining influence on its dynamics.

In the article it is investigated proposed by authors the mathematical model of determination of the functional dependence of the magnitude of the frontal air resistance force of the projectile's motion on its velocity, mass and caliber, geometric characteristics, temperature and density of air, atmospheric pressure, sound speed in air.

Since the trajectory of movement of the BM1 projectile released from the T-12 (MT-12) is canopy, it is assumed that during the projectile's flight the air temperature and atmospheric pressure are unchanged and equal to their value at the point of the gun.
\end{abstract}

Citation: Л. Д. Величко, I. В. Горчинський, М. І. Сорокатий. (2020) Zovnishnia Balistyka Snariadu BM1 Vypushchenoho z T-12 (MT-12). World Science. 1(53), Vol.1. doi: 10.31435/rsglobal_ws/31012020/6891

Copyright: (C) 2020 Л. Д. Величко, І. В. Горчинський, М. І. Сорокатий. This is an open-access article distributed under the terms of the Creative Commons Attribution License (CC BY). The use, distribution or reproduction in other forums is permitted, provided the original author(s) or licensor are credited and that the original publication in this journal is cited, in accordance with accepted academic practice. No use, distribution or reproduction is permitted which does not comply with these terms.

Постановка проблеми. Значення параметрів руху снаряду в повітрі залежить від детермінованих (форми і маси снаряду, густини і температури повітря, атмосферного тиску, деривації) та недетермінованих (дульної швидкості, величини і напрямку швидкості вітру) факторів. Однією з основних сил, яка суттєво впливає на динаміку руху снаряду в повітрі, $є$ сила лобового опору повітря. Значення коефіцієнту форми снаряду та еталонної функції лобового опору повітря визначають використовуючи результати експериментальних досліджень. Величини поправок, обумовлені нестандартними умовами стрільби та наведені в таблицях стрільб, визначені розкладом в степеневий ряд функціональної залежності дальності лету снаряду від початкової швидкості снаряду, кута прицілювання та балістичного коефіцієнту. Оскільки до уваги беруться лише перші члени розкладу, то рекомендації стрільби, які приведені в таблицях стрільб, не завжди задовольняють практику їх використання. Отже, $є$ потреба, на основі поєднання експериментальних та теоретичних досліджень, розробити математичний апарат скерований на покращення точності стрільби.

Аналіз останніх досліджень і публікацій. Основи теоретичних досліджень зовнішньої балістики куль та снарядів викладені, наприклад, в роботах [1-3]. У них та наукових статтях [49] сила лобового опору повітря описується залежністю 


$$
R=\frac{\rho V^{2}}{2} \frac{\pi d^{2}}{4} i c_{x}\left(\frac{V}{V_{s}}\right)
$$

де $R$ - сила лобового опору повітря, $V$ - швидкість снаряду, $\rho$ - густина повітря, $V_{s}-$ швидкість звуку в повітрі, $d$ - калібр снаряда, $i$ - коефіцієнт форми снаряда, $c_{x}\left(\frac{V}{a}\right)$ - еталонна функція лобового опору. У статті [10] досліджується зовнішня балістика кулі, випущеної із СВД. У ній відмовились від застосування еталонних функцій лобового опору на користь індивідуальної функції лобового опору повітря для кулі випущеної з цієї зброї.

Формулювання мети статті. Базуючись тільки на аналітичних методах проблематично визначити функціональну залежність величини сили лобового опору повітря рухові снаряду від детермінованих та недетермінованих факторів. У статті пропонується математична модель іiі визначення, яка базується на розв'язуванні оберненої задачі динаміки 3 використанням теоретичних та експериментальних досліджень. На основі встановленої функціональної залежності визначаються величини поправок обумовлених нестандартними умовами стрільби та порівнюються з табличними значеннями.

Виклад основного матеріалу. Згідно результатів експериментальних досліджень величина сили лобового опору повітря рухові тіла пропорціональна його швидкості в певній степені і вона необов'язково друга. Крім того, величина сили лобового опору повітря суттєвою залежить від того чи швидкість руху тіла $\epsilon$ надзвуковою, чи - дозвуковою. Підкаліберний снаряд БМ1, випущений 3 протитанкової гармати Т-12, починає рухатись 3 надзвуковою швидкістю і в таблицях стрільб вказані результати експериментальних досліджень при цих швидкостях.

Пропонується функціональну залежність величини сили лобового опору повітря рухові снаряду описувати формулою

$$
R(t)=c_{x} \cdot \rho_{a} \cdot s_{x} \cdot(V(t))^{2+\gamma} \cdot\left(\frac{V(t)}{V_{s}}\right)^{\beta} ;
$$

де $c_{x}$ - коефіцієнт, який враховує аеродинамічність форми кулі та пропорційності; $\rho_{a}-$ густина повітря; $s_{x}$ - максимальна площа поперечного перерізу снаряду площиною перпендикулярною до напрямку його швидкості; $V(t)$ - швидкість снаряду в довільний момент часу; $V_{s}$ - швидкість звуку в повітрі; $\gamma$ i $\beta$ - коефіцієнти, величини яких визначають використовуючи результати експериментальних досліджень.

Вирішальний вплив на динаміку руху снаряду в повітрі відіграють його вага $\vec{P}$ та сила лобового опору повітря $\vec{R}$. Впливом сил Магнуса, Коріоліса та підіймальною для снаряду БМ1 можна знехтувати.

На основі другого закону динаміки запишеться рівняння

$$
m \vec{a}=\vec{P}+\vec{R},
$$

де $m$ - маса і $\vec{a}$ - пришвидшення снаряду.

Вибираємо початок системи координат $O x z$ в точці вильоту снаряду. Вісь $O x$ розміщуємо в площині зброї, а вісь $O z$ - скеровуємо вертикально вгору.

Проектуючи рівняння (2) на осі координат і враховуючи (1), отримаємо

$$
\begin{gathered}
m \ddot{x}=-c_{x} \cdot \rho_{a} \cdot s_{x} \cdot(V(t))^{2+\gamma}\left(\frac{V(t)}{V_{s}}\right)^{\beta} \cos \theta, \\
m \ddot{z}=-m g-c_{x} \cdot \rho_{a} \cdot s_{x} \cdot(V(t))^{2+\gamma}\left(\frac{V(t)}{V_{s}}\right)^{\beta} \sin \theta,
\end{gathered}
$$

де $g=9,81 \mathrm{M} / \mathrm{c}^{2}-$ прискорення вільного падіння тіла, $\theta$ - кут нахилу вектора швидкості кулі до горизонту в довільний момент часу.

Враховуючи, що

$$
\cos \theta=\frac{V_{x}}{V}, \sin \theta=\frac{V_{z}}{V}, V_{x}(t)=\dot{x}(t), V_{z}(t)=\dot{z}(t) \text { i } V(t)=\sqrt{(\dot{x}(t))^{2}+(\dot{z}(t))^{2}},
$$


залежності (3) і (4) набудуть вигляду

$$
\begin{gathered}
m \ddot{x}=-\frac{c_{x} \rho_{a} s_{x} \dot{x}}{V_{s}^{\beta}}\left(\dot{x}^{2}+\dot{z}^{2}\right)^{0,5(1+\gamma+\beta)}, \\
m \ddot{z}=-m g-\frac{c_{x} \rho_{a} s_{x} \dot{z}}{V_{s}^{\beta}}\left(\dot{x}^{2}+\dot{z}^{2}\right)^{0,5(1+\gamma+\beta)} .
\end{gathered}
$$

Початкові умови для системи диференціальних рівнянь наступні:

$$
x(0)=0, \dot{x}(0)=V_{0} \cos \alpha, z(0)=0, \dot{\mathrm{i}} \dot{z}(0)=V_{0} \sin \alpha,
$$

де $V_{0}$ - початкова швидкість снаряду, $\alpha$ - кут прицілювання.

Під час проведення експериментальних досліджень та їх опрацювання отримано числові значення: $\alpha$ - кута прицілювання; $t_{k}$ - тривалості лету снаряду; $x\left(t_{k}\right)$ - координати точки обнуління траєкторії; $\theta_{c}$ - кута падіння; $V\left(t_{k}\right)$ - кінцевої швидкості снаряду і $H$ максимальної висоти траєкторії.

Отже, обернена задача динаміки полягає у визначенні значень сталих величин $c_{x}, \gamma$ i $\beta$, які при розв'язуванні системи диференціальних рівнянь (6) і (7) з початковими умовами (8) забезпечували б незначну розбіжність між теоретичними та експериментальними результатами. Їх значення визначали використовуючи метод послідовних наближень та отримали $c_{x}=0,3$, $\gamma=-0,003$ i $\beta=-0,352$.

При здійсненні обчислень брались значення: маса снаряду $m=3,38 \kappa 2$, початкова швидкість $V_{0}=1575 \mathrm{M} / \mathrm{c}$, площа поперечного перерізу снаряду $s_{x}=\pi \cdot 0,021^{2} \mathrm{M}^{2}$, температура повітря $t_{a}=15^{0} C$, атмосферний тиск $p=750$ мм $\quad p m . \quad c m$., густина повітря $\rho_{a}=1,20937 \mathrm{k} / \mathrm{m}^{3}$.

\begin{tabular}{|c|c|c|c|c|c|c|c|}
\hline $\begin{array}{l}\alpha, \\
\text { град. хв.сек }\end{array}$ & $t_{k}, c$ & $\begin{array}{l}\theta_{c}, \\
\text { град. хв.сек }\end{array}$ & $\begin{array}{l}x\left(t_{k}\right), \\
\mathcal{M}\end{array}$ & $\begin{array}{l}\dot{x}\left(t_{k}\right), \\
\mu / c\end{array}$ & $\begin{array}{l}\dot{z}\left(t_{k}\right), \\
M / c\end{array}$ & $\begin{array}{l}V\left(t_{k}\right), \\
\mathcal{M} / c\end{array}$ & $\begin{array}{r}H \\
\mathcal{M}\end{array}$ \\
\hline $\begin{array}{llll}0 & 00 & 41\end{array}$ & $\begin{array}{l}0,0638 \\
(0,063)\end{array}$ & $\begin{array}{l}\left.\begin{array}{lll}0 & 00 & 41 \\
(0 & 00\end{array}\right)\end{array}$ & $\begin{array}{l}99,90 \\
(100)\end{array}$ & 1561,67 & $-0,31$ & $\begin{array}{l}1561,67 \\
(1561)\end{array}$ & $\begin{array}{l}0,005 \\
(0,0)\end{array}$ \\
\hline $\begin{array}{llll}0 & 02 & 47\end{array}$ & $\begin{array}{l}0,2585 \\
(0,258)\end{array}$ & $\begin{array}{lll}0 & 02 & 51 \\
\left(\begin{array}{ll}0 & 02\end{array}\right)\end{array}$ & $\begin{array}{l}400,24 \\
(400)\end{array}$ & 1522,11 & $-1,26$ & $\begin{array}{l}1522,12 \\
(1521)\end{array}$ & $\begin{array}{l}0,082 \\
(0,1)\end{array}$ \\
\hline 00457 & $\begin{array}{l}0,4577 \\
(0,458)\end{array}$ & 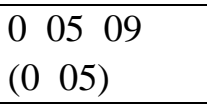 & $\begin{array}{l}699,55 \\
(700)\end{array}$ & 1483,32 & $-2,22$ & $\begin{array}{l}1483,33 \\
(1482)\end{array}$ & $\begin{array}{l}0,257 \\
(0,3)\end{array}$ \\
\hline $\begin{array}{lll}0 & 07 & 12\end{array}$ & $\begin{array}{l}0,6628 \\
(0,664)\end{array}$ & $\begin{array}{lll}0 & 07 & 38 \\
\left(\begin{array}{ll}0 & 07\end{array}\right)\end{array}$ & $\begin{array}{l}999,83 \\
(1000)\end{array}$ & 1445,06 & $-3,21$ & $\begin{array}{l}1445,06 \\
(1444)\end{array}$ & $\begin{array}{l}0,539 \\
(0,5)\end{array}$ \\
\hline $\begin{array}{lll} & 09 & 32\end{array}$ & $\begin{array}{l}0,8735 \\
(0,873)\end{array}$ & $\begin{array}{lll}0 & 10 & 16 \\
\left(\begin{array}{ll}0 & 10\end{array}\right)\end{array}$ & $\begin{array}{l}1300,31 \\
(1300)\end{array}$ & 1407,41 & $-4,21$ & $\begin{array}{l}1407,41 \\
(1407)\end{array}$ & $\begin{array}{l}0,936 \\
(0,9)\end{array}$ \\
\hline $\begin{array}{lll}0 & 1157\end{array}$ & $\begin{array}{l}1,0898 \\
(1,089)\end{array}$ & $\begin{array}{lll}0 & 13 & 07 \\
\left(\begin{array}{ll}0 & 13\end{array}\right)\end{array}$ & $\begin{array}{l}1600,70 \\
(1600)\end{array}$ & 1370,41 & $-5,23$ & $\begin{array}{l}1370,42 \\
(1371)\end{array}$ & $\begin{array}{l}1,457 \\
(1,5)\end{array}$ \\
\hline $\begin{array}{lll}0 & 14 & 27\end{array}$ & $\begin{array}{l}1,3115 \\
(1,311)\end{array}$ & 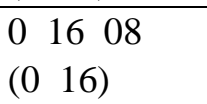 & $\begin{array}{l}1900,47 \\
(1900)\end{array}$ & 1334,12 & $-6,26$ & $\begin{array}{l}1334,14 \\
(1336)\end{array}$ & $\begin{array}{l}2,110 \\
(2,1)\end{array}$ \\
\hline $\begin{array}{lll}0 & 17 & 02\end{array}$ & $\begin{array}{l}1,5384 \\
(1,538)\end{array}$ & 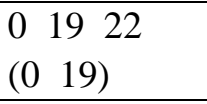 & $\begin{array}{l}2199,12 \\
(2200)\end{array}$ & 1298,60 & $-7,32$ & $\begin{array}{l}1298,62 \\
(1302)\end{array}$ & $\begin{array}{l}2,903 \\
(2,9)\end{array}$ \\
\hline $\begin{array}{lll}0 & 19 & 43\end{array}$ & $\begin{array}{l}1,7718 \\
(1,771) \\
\end{array}$ & 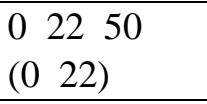 & $\begin{array}{l}2498,11 \\
(2500) \\
\end{array}$ & 1263,66 & $-8,39$ & $\begin{array}{l}1263,69 \\
(1269) \\
\end{array}$ & $\begin{array}{l}3,852 \\
(3,8) \\
\end{array}$ \\
\hline 02230 & $\begin{array}{l}2,0116 \\
(2,011)\end{array}$ & 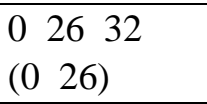 & $\begin{array}{l}2797,00 \\
(2800)\end{array}$ & 1229,35 & $-9,49$ & $\begin{array}{l}1229,39 \\
(1237)\end{array}$ & $\begin{array}{l}4,966 \\
(5,0)\end{array}$ \\
\hline $\begin{array}{lll}0 & 24 & 25\end{array}$ & $\begin{array}{l}2,1754 \\
(2,174)\end{array}$ & $\begin{array}{lll}0 & 29 & 09 \\
\left(\begin{array}{ll}0 & 29\end{array}\right)\end{array}$ & $\begin{array}{l}2996,52 \\
(3000)\end{array}$ & 1206,79 & $-10,23$ & $\begin{array}{l}1206,83 \\
(1215)\end{array}$ & $\begin{array}{l}5,808 \\
(5,8)\end{array}$ \\
\hline
\end{tabular}

Таблиця 1. Значення теоретичних і експериментальних кінематичних параметрів руху снаряду БМ1, випущеного з Т-12 (МТ-12) 
У таблиці 1 в дужках вказані величини параметрів, які визначенні експериментально або теоретично та приведені в [11]. $\dot{x}\left(t_{k}\right) \dot{\text { i }} \dot{z}\left(t_{k}\right)$ - проекції швидкості снаряду на відповідні осі координат в момент обнуління траєкторії руху снаряду.

Порівнюючи отримані теоретичні значення кінематичних параметрів руху снаряду, приведені в таблиці 1, 3 результатами в таблицях стрільб [11], можна стверджувати, що розбіжність між ними є меншою одного відсотка.

Вплив температури повітря на рух снаряду. Оскільки траєкторія руху снаряду БМ1 випущеного $з$ протитанкової гармати Т-12 (МТ-12) полога, то вважається, що температура повітря не змінюється під час його руху.

При зміні температури повітря змінюються швидкість звуку в повітрі та його густина. Величина швидкості звуку в повітрі визначається з використанням формули [12]

$$
V_{s}=\sqrt{\frac{k R T}{\mu}},
$$

де: $k$ - показник адіабати і для повітря $k=1,4 ; R=8314 \frac{\text { Дж }}{K \cdot \text { кмоль }}-$ універсальна газова стала, $T$ - абсолютна температура повітря; $\mu=28,96 \frac{\kappa 2}{\kappa м о л ь}-$ умовна молярна маса повітря.

Використовуючи рівняння Клапейрона-Менделєєва

$$
p V=\frac{m R T}{\mu}
$$

та враховуючи, що густина речовини визначається $з$ допомогою формули

$$
\rho=\frac{m}{V},
$$

отримаємо рівняння для визначення густини повітря

$$
\rho_{a}=\frac{\mu p}{R T},
$$

де $p$ - абсолютний тиск повітря.

Використовуючи залежності (9) і (12), визначаються значення густини повітря та швидкості звуку при певній температурі. Ці значення підставляються в систему диференціальних рівнянь (6) і

\begin{tabular}{|c|c|c|c|c|c|c|c|c|}
\hline $\begin{array}{l}\alpha, \\
\text { град. хв. сек }\end{array}$ & $t_{a}$ & $-25^{0} \mathrm{C}$ & $-15^{0} C$ & $-5^{0} C$ & $5^{0} \mathrm{C}$ & $15^{0} \mathrm{C}$ & $25^{0} \mathrm{C}$ & $35^{0} \mathrm{C}$ \\
\hline 1 & 2 & 3 & 4 & 5 & 6 & 7 & 8 & 9 \\
\hline $\begin{array}{lll}0 & 00 & 41\end{array}$ & $\begin{array}{l}x_{k}, M \\
\Delta x_{\text {theo }}, M \\
\Delta x_{\text {tabl }}, M\end{array}$ & $\begin{array}{l}99,85 \\
-0,05 \\
0,0\end{array}$ & $\begin{array}{l}99,86 \\
-0,04 \\
0,0\end{array}$ & $\begin{array}{l}99,88 \\
-0,02 \\
0,0\end{array}$ & $\begin{array}{l}99,89 \\
-0,01 \\
0,0\end{array}$ & $\begin{array}{l}99,90 \\
0,0 \\
0,0\end{array}$ & $\begin{array}{l}99,91 \\
0,01 \\
0,0\end{array}$ & $\begin{array}{l}99,92 \\
0,02 \\
0,0 \\
\end{array}$ \\
\hline $\begin{array}{llll}0 & 02 & 47\end{array}$ & $\begin{array}{l}x_{k}, M \\
\Delta x_{\text {theo }}, M \\
\Delta x_{\text {tabl }}, M\end{array}$ & $\begin{array}{l}399,05 \\
-1,19 \\
0,0\end{array}$ & $\begin{array}{l}399,44 \\
-0,80 \\
0,0\end{array}$ & $\begin{array}{l}399,67 \\
-0,57 \\
0,0\end{array}$ & $\begin{array}{l}400,04 \\
-0,20 \\
0,0\end{array}$ & $\begin{array}{l}400,24 \\
0,0 \\
0,0\end{array}$ & $\begin{array}{l}400,58 \\
0,34 \\
0,0\end{array}$ & $\begin{array}{l}400,76 \\
0,52 \\
0,0\end{array}$ \\
\hline $\begin{array}{lll}0 & 04 & 57\end{array}$ & $\begin{array}{l}x_{k}, M \\
\Delta x_{\text {theo }}, M \\
\Delta x_{\text {tabl }}, M\end{array}$ & $\begin{array}{l}695,97 \\
-3,58 \\
-4,0\end{array}$ & $\begin{array}{l}697,01 \\
-2,54 \\
-3,0\end{array}$ & $\begin{array}{l}698,00 \\
-1,55 \\
-2,0\end{array}$ & $\begin{array}{l}698,79 \\
-0,76 \\
-1,0\end{array}$ & $\begin{array}{l}699,55 \\
0,0 \\
0,0\end{array}$ & $\begin{array}{l}700,42 \\
0,87 \\
1,0\end{array}$ & $\begin{array}{l}701,11 \\
1,56 \\
2,0\end{array}$ \\
\hline $\begin{array}{lll}0 & 07 & 12\end{array}$ & $\begin{array}{l}x_{k}, M \\
\Delta x_{\text {theo }}, M \\
\Delta x_{\text {tabl }}, M\end{array}$ & $\begin{array}{l}992,49 \\
-7,34 \\
-8,0\end{array}$ & $\begin{array}{l}994,57 \\
-5,26 \\
-6,0\end{array}$ & $\begin{array}{l}996,40 \\
-3,43 \\
-4,0\end{array}$ & $\begin{array}{l}998,16 \\
-1,67 \\
-2,0\end{array}$ & $\begin{array}{l}999,83 \\
0,0 \\
0,0\end{array}$ & $\begin{array}{l}1001,28 \\
1,45 \\
2,0\end{array}$ & $\begin{array}{l}1002,82 \\
2,99 \\
4,0\end{array}$ \\
\hline $\begin{array}{lll}0 & 09 & 32\end{array}$ & $\begin{array}{l}x_{k}, M \\
\Delta x_{\text {theo }}, M \\
\Delta x_{\text {tabl }}, M\end{array}$ & $\begin{array}{l}1288,16 \\
-12,15 \\
-12,0\end{array}$ & $\begin{array}{l}1291,52 \\
-8,79 \\
-9,0\end{array}$ & $\begin{array}{l}1294,69 \\
-5,72 \\
-6,0\end{array}$ & $\begin{array}{l}1297,51 \\
-2,80 \\
-3,0\end{array}$ & $\begin{array}{l}1300,31 \\
0,0 \\
0,0\end{array}$ & $\begin{array}{l}1302,98 \\
2,67 \\
3,0\end{array}$ & $\begin{array}{l}1305,41 \\
5,10 \\
6,0\end{array}$ \\
\hline
\end{tabular}
(7), яка розв'язується з використанням програмного забезпечення.

Таблиця 2. Зміщення координати точки обнуління траєкторії руху снаряду при зміні температури повітря 
Продовження таблиці 2

\begin{tabular}{|c|c|c|c|c|c|c|c|c|}
\hline 1 & 2 & 3 & 4 & 5 & 6 & 7 & 8 & 9 \\
\hline \multirow[t]{3}{*}{$\begin{array}{llll}0 & 11 & 5\end{array}$} & $x_{k}, M$ & 1582,32 & 1587,35 & 1592,14 & 1596,58 & 1600,70 & 1604,64 & 1608,42 \\
\hline & $\Delta x_{\text {theo }}, M$ & $-18,38$ & $-13,35$ & $-8,56$ & $-4,12$ & 0,0 & 3,94 & 7,72 \\
\hline & $\Delta x_{t a b l}, M$ & $-20,0$ & $-15,0$ & $-10,0$ & $-5,0$ & 0,0 & 5,0 & 10,0 \\
\hline \multirow[t]{3}{*}{$\begin{array}{llll}0 & 14 & 2\end{array}$} & $x_{k}, M$ & 1874,64 & 1881,68 & 1888,40 & 1894,56 & 1000,47 & 1906,00 & 1911,18 \\
\hline & $\Delta x_{\text {theo }}, M$ & $-25,83$ & $-18,79$ & $-12,07$ & $-5,91$ & 0,0 & 5,53 & 10,71 \\
\hline & $\Delta x_{t a b l}, M$ & $-28,0$ & $-21,0$ & $-14,0$ & $-7,0$ & 0,0 & 7,0 & 14,0 \\
\hline \multirow[t]{3}{*}{$\begin{array}{lll}0 & 17 & 02\end{array}$} & $x_{k}, M$ & 2164,94 & 2174,19 & 2183,04 & 2191,25 & 2199,12 & 2206,42 & 2213,45 \\
\hline & $\Delta x_{\text {theo }}, M$ & $-34,18$ & $-24,93$ & $-16,08$ & $-7,87$ & 0,0 & 7,30 & 14,31 \\
\hline & $\Delta x_{t a b l}, M$ & $-36,0$ & $-27,0$ & $-18,0$ & $-9,0$ & 0,0 & 9,0 & 18,0 \\
\hline \multirow[t]{3}{*}{$\begin{array}{llll}0 & 19 & 4\end{array}$} & $x_{k}, M$ & 2454,28 & 2466,22 & 2477,52 & 2488,09 & 2498,11 & 2507,61 & 2516,62 \\
\hline & $\Delta x_{\text {theo }}, \mu$ & $-43,83$ & $-31,89$ & $-20,59$ & $-10,02$ & 0,0 & 9,50 & 18,51 \\
\hline & $\Delta x_{t a b l}, M$ & $-48,0$ & $-36,0$ & $-24,0$ & $-12,0$ & 0,0 & 12,0 & 24,0 \\
\hline \multirow[t]{3}{*}{$\begin{array}{llll}0 & 22 & 3\end{array}$} & $x_{k}, M$ & 2742,42 & 2757,23 & 2771,29 & 2784,53 & 2797,00 & 2808,87 & 2820,16 \\
\hline & $\Delta x_{\text {theo }}, M$ & $-54,58$ & $-39,77$ & $-25,71$ & $-12,47$ & 0,0 & 11,87 & 23,16 \\
\hline & $\Delta x_{t a b l}, M$ & $-56,0$ & $-42,0$ & $-28,0$ & $-14,0$ & 0,0 & 14,0 & 28,0 \\
\hline \multirow[t]{3}{*}{0242} & $x_{k}, M$ & 2934,05 & 2951,00 & 2967,00 & 2982,12 & 2996,52 & 3010,02 & 3022,89 \\
\hline & $\Delta x_{\text {theo }}, M$ & $-62,47$ & $-45,52$ & $-29,52$ & $-14,40$ & 0,0 & 13,50 & 26,37 \\
\hline & $\Delta x_{t a b l}, M$ & $-64,0$ & $-48,0$ & $-32,0$ & $-16,0$ & 0,0 & 16,0 & 32,0 \\
\hline
\end{tabular}

У таблиці 2: $t_{a}$ - температура повітря; $\Delta x_{t h e o}$ i $\Delta x_{t a b l}$ - величини зміщення точки обнуління траєкторії руху снаряду визначені запропонованим методом та вказаних в таблицях стрільб [11]; знак (-) вказує, що снаряд не долітає.

Вплив зміни атмосферного тиску на рух снаряду. Атмосферний тиск впливає на величину густини повітря. Підставляючи його значення в рівняння (12) визначається густина повітря. Ї̈̈ значення враховується при розв'язуванні системи диференціальних рівнянь (6) і (7) 3 початковою умовою (8).

Таблиця 3. Зміщення координати точки обнуління траєкторії руху снаряду при зміні атмосферного тиску

\begin{tabular}{|c|c|c|c|c|c|c|c|}
\hline $\begin{array}{l}\alpha, \\
\text { град. хв. сек }\end{array}$ & & $\begin{array}{l}590 \\
\text { мм pm cm }\end{array}$ & $\begin{array}{l}670 \\
\text { мм pm cm }\end{array}$ & $\begin{array}{l}710 \\
\text { мм pm cm }\end{array}$ & $\begin{array}{l}740 \\
\text { мм pm cm }\end{array}$ & $\begin{array}{l}750 \\
\text { мм pm cm }\end{array}$ & $\begin{array}{l}760 \\
\text { мм pm cm }\end{array}$ \\
\hline $\begin{array}{llll}0 & 00 & 41\end{array}$ & $\begin{array}{l}x_{k}, M \\
\Delta x_{\text {theo }}, M \\
\Delta x_{t a b l}, M\end{array}$ & $\begin{array}{l}99,99 \\
0,09 \\
0,0\end{array}$ & $\begin{array}{l}99,95 \\
0,05 \\
0,0\end{array}$ & $\begin{array}{l}99,92 \\
0,02 \\
0,0 \\
\end{array}$ & $\begin{array}{l}99,91 \\
0,01 \\
0,0 \\
\end{array}$ & $\begin{array}{l}99,90 \\
0,0 \\
0,0\end{array}$ & $\begin{array}{l}99,90 \\
0,00 \\
0,0 \\
\end{array}$ \\
\hline $\begin{array}{llll} & 04 & 57\end{array}$ & $\begin{array}{l}x_{k}, M \\
\Delta x_{\text {theo }}, M \\
\Delta x_{\text {tabl }}, M\end{array}$ & $\begin{array}{l}705,49 \\
5,94 \\
0,0\end{array}$ & $\begin{array}{l}702,51 \\
2,96 \\
-28,0 \\
\end{array}$ & $\begin{array}{l}701,10 \\
1,55 \\
0,0\end{array}$ & $\begin{array}{l}699,98 \\
0,43 \\
0,0\end{array}$ & $\begin{array}{l}699,55 \\
0,0 \\
0,0\end{array}$ & $\begin{array}{l}699,28 \\
-0,27 \\
0,0 \\
\end{array}$ \\
\hline $\begin{array}{llll}0 & 09 & 32\end{array}$ & $\begin{array}{l}x_{k}, M \\
\Delta x_{t h e o}, M \\
\Delta x_{t a b l}, M\end{array}$ & $\begin{array}{l}1320,68 \\
20,37 \\
16,0\end{array}$ & $\begin{array}{l}1310,48 \\
10,17 \\
8,0\end{array}$ & $\begin{array}{l}1305,38 \\
5,07 \\
4,0\end{array}$ & $\begin{array}{l}1301,53 \\
1,22 \\
1,0\end{array}$ & $\begin{array}{l}1300,31 \\
0,0 \\
0,0\end{array}$ & $\begin{array}{l}1299,08 \\
-1,23 \\
-1,0\end{array}$ \\
\hline $\begin{array}{ll}0 & 12\end{array}$ & $\begin{array}{l}x_{k}, M \\
\Delta x_{\text {theo }}, M \\
\Delta x_{\text {tabl }}, M\end{array}$ & $\begin{array}{l}1944,00 \\
43,53 \\
48,0\end{array}$ & $\begin{array}{l}1921,85 \\
21,38 \\
24,0\end{array}$ & $\begin{array}{l}1911,10 \\
10,63 \\
12,0\end{array}$ & $\begin{array}{l}1903,01 \\
2,54 \\
3,0\end{array}$ & $\begin{array}{l}1900,47 \\
0,0 \\
0,0\end{array}$ & $\begin{array}{l}1897,79 \\
-2,68 \\
-3,0\end{array}$ \\
\hline $0 \quad 1943$ & $\begin{array}{l}x_{k}, M \\
\Delta x_{\text {theo }}, M \\
\Delta x_{\text {tabl }}, M\end{array}$ & $\begin{array}{l}2573,26 \\
75,15 \\
64,0 \\
\end{array}$ & $\begin{array}{l}2535,14 \\
37,03 \\
32,0\end{array}$ & $\begin{array}{l}2516,49 \\
18,38 \\
16,0\end{array}$ & $\begin{array}{l}2502,71 \\
4,60 \\
4,0 \\
\end{array}$ & $\begin{array}{l}2498,11 \\
0,0 \\
0,0 \\
\end{array}$ & $\begin{array}{l}2493,53 \\
-4,58 \\
-4,0 \\
\end{array}$ \\
\hline 02425 & $\begin{array}{l}x_{k}, M \\
\Delta x_{\text {theo }}, M \\
\Delta x_{\text {tabl }}, M\end{array}$ & $\begin{array}{l}3104,53 \\
108,01 \\
96,0\end{array}$ & $\begin{array}{l}3049,46 \\
52,94 \\
48,0\end{array}$ & $\begin{array}{l}3022,70 \\
26,18 \\
24,0\end{array}$ & $\begin{array}{l}3002,93 \\
6,41 \\
6,0\end{array}$ & $\begin{array}{l}2996,52 \\
0,0 \\
0,0\end{array}$ & $\begin{array}{l}2990,01 \\
-6,51 \\
-6,0\end{array}$ \\
\hline
\end{tabular}


Вплив зміни початкової швидкості снаряду на його рух. Щоб врахувати вплив зміни тільки початкової швидкості снаряду на його рух в повітрі, необхідно розв'язувати систему диференціальних рівнянь (6) і (7) при початкових умовах (8) 3 конкретним значенням початкової швидкості снаряду.

Таблиця 4. Зміщення координати точки обнуління траєкторії руху снаряду при зміні його початкової швидкості

\begin{tabular}{|c|c|c|c|c|c|c|c|}
\hline $\begin{array}{l}\alpha, \\
\text { град. хв.сек }\end{array}$ & & $V_{0}-3 \% V_{0}$ & $V_{0}-2 \% V_{0}$ & $V_{0}-1 \% V_{0}$ & $V_{0}$ & $V_{0}+1 \% V_{0}$ & $V_{0}+2 \% V_{0}$ \\
\hline $\begin{array}{llll}0 & 00 & 41\end{array}$ & $\begin{array}{l}x_{k}, M \\
\Delta x_{\text {theo }}, M \\
\Delta x_{\text {tabl }}, M\end{array}$ & $\begin{array}{l}94,03 \\
-5,87 \\
-6,0\end{array}$ & $\begin{array}{l}96,07 \\
-3,83 \\
-4,0 \\
\end{array}$ & $\begin{array}{l}97,98 \\
-1,92 \\
-2,0 \\
\end{array}$ & $\begin{array}{l}99,90 \\
0,0 \\
0,0\end{array}$ & $\begin{array}{l}102,00 \\
2,10 \\
2,0\end{array}$ & $\begin{array}{l}103,96 \\
4,06 \\
4,0\end{array}$ \\
\hline 00457 & $\begin{array}{l}x_{k}, M \\
\Delta x_{t h e o}, M \\
\Delta x_{t a b l}, M\end{array}$ & $\begin{array}{l}659,49 \\
-40,06 \\
-42,0\end{array}$ & $\begin{array}{l}672,72 \\
-26,83 \\
-28,0\end{array}$ & $\begin{array}{l}686,07 \\
-13,48 \\
-14,0\end{array}$ & $\begin{array}{l}699,55 \\
0,0 \\
0,0\end{array}$ & $\begin{array}{l}713,15 \\
13,60 \\
14,0\end{array}$ & $\begin{array}{l}726,87 \\
27,32 \\
28,0\end{array}$ \\
\hline $\begin{array}{lll}0 & 09 & 32\end{array}$ & $\begin{array}{l}x_{k}, M \\
\Delta x_{\text {theo }}, M \\
\Delta x_{\text {tabl }}, M\end{array}$ & $\begin{array}{l}1227,83 \\
-72,48 \\
-72,0 \\
\end{array}$ & $\begin{array}{l}1251,83 \\
-48,48 \\
-48,0\end{array}$ & $\begin{array}{l}1275,90 \\
-24,41 \\
-24,0 \\
\end{array}$ & $\begin{array}{l}1300,31 \\
0,0 \\
0,0\end{array}$ & $\begin{array}{l}1324,92 \\
24,61 \\
24,0 \\
\end{array}$ & $\begin{array}{l}1349,58 \\
49,27 \\
48,0\end{array}$ \\
\hline $\begin{array}{lll}0 & 14 & 27\end{array}$ & $\begin{array}{l}x_{k}, M \\
\Delta x_{\text {theo }}, M \\
\Delta x_{\text {tabl }}, M\end{array}$ & $\begin{array}{l}1797,26 \\
-103,21 \\
-102,0 \\
\end{array}$ & $\begin{array}{l}1831,44 \\
-69,03 \\
-68,0\end{array}$ & $\begin{array}{l}1865,76 \\
-34,71 \\
-34,0 \\
\end{array}$ & $\begin{array}{l}1900,47 \\
0,0 \\
0,0\end{array}$ & $\begin{array}{l}1935,30 \\
34,83 \\
34,0 \\
\end{array}$ & $\begin{array}{l}1970,40 \\
69,93 \\
68,0 \\
\end{array}$ \\
\hline $\begin{array}{lll}0 & 19 & 43\end{array}$ & $\begin{array}{l}x_{k}, M \\
\Delta x_{\text {theo }}, M \\
\Delta x_{\text {tabl }}, M\end{array}$ & $\begin{array}{l}2366,23 \\
-131,88 \\
-129,0\end{array}$ & $\begin{array}{l}2409,89 \\
-88,22 \\
-86,0\end{array}$ & $\begin{array}{l}2453,85 \\
-44,26 \\
-12,0\end{array}$ & $\begin{array}{l}2498,11 \\
0,0 \\
0,0\end{array}$ & $\begin{array}{l}2542,55 \\
44,44 \\
43,0\end{array}$ & $\begin{array}{l}2587,41 \\
89,30 \\
86,0\end{array}$ \\
\hline
\end{tabular}

Запропонована математична модель дозволяє визначати кінематичні параметри руху снаряду в повітрі при фізично обгрунтованих значеннях температур повітря, початкової швидкості та маси снаряду, атмосферного тиску тощо.

Наприклад, вважається, що здійснюється стрільба на віддаль 2000 метрів при наступних значеннях: $t_{a}=-25^{0} C$ - температура повітря, $V_{0}=1606,5 \mathrm{~m} / \mathrm{c}$ - початкова швидкість снаряду, $p=710$ мм pm cm - атмосферний тиск. Використовуючи залежності (9) i (12) визначаються величини швидкості звуку та густину повітря. Потім підставляють їх значення у систему диференціальних рівнянь (6) і (7). Розв'язують іiі враховуючи початкові умови (8). Отримали: $t_{k}=1,4098 c$ - тривалість руху снаряду, $x\left(t_{k}\right)=2056,82 \mu$ - координата точки обнуління траєкторії, $\dot{x}\left(t_{k}\right)=1326,05 \mathrm{M} / \mathrm{c}$ i $\dot{z}\left(t_{k}\right)=-6,71 \mathrm{M} / \mathrm{c}$ - проекції швидкості снаряду на відповідні осі координат в момент обнуління траєкторії, $V\left(t_{k}\right)=314,08 \mathrm{M} / \mathrm{c}$ - кінцева швидкість снаряду, $H=2,44 \mu$ - максимальна висота траєкторії, $x_{H}=1061,1$ м - горизонтальна дальність до вершини траєкторії. Отже, координата точки обнуління траєкторії, визначена теоретично, зміститься на $+56,82 \mathrm{M}$.

Згідно поправок, вказаних в таблицях стрільб [11], отримаємо, що координата точки обнуління траєкторії, при вказаних вище умовах, зміниться на величину 52 метри.

Висновки. Розбіжності між результатами теоретичних досліджень і величинами поправок приведених в таблицях [11] є внаслідок того, що останні визначались розкладом відповідних залежностей в числові ряди 3 врахуванням лише перших членів розкладу та похибками при визначенні коефіцієнту форми снаряду і функції лобового опору.

Знаючи функціональну залежність (1) можна визначати вплив змін температур повітря і заряду снаряду, атмосферного тиску, початкової швидкості снаряду та його маси, величини супутнього або зустрічного вітру на кінематичні параметри руху.

Запропонована математична модель визначення сили лобового опору повітря рухові снаряду дасть можливість визначати кут прицілювання для стрільби на більші віддалі, ніж вказані у таблицях стрільб, з врахуванням нестандартних умов. 


\section{REFERENCES}

1. Chernozubov, A.D., Kyrychenko, A.D., Razin, I.I. and Mykhajlov, K.V. (1954), "Vneschnaya balistica. Chast 1" [External ballistics. Part I], Printing house of the Artillery Engineering Academy, 467 p.

2. Chernozubov, A.D., Kyrychenko, A.D., Razin, I.I. and Mykhajlov, K.V. (1954), "Vneschnaya balistica. Chast 1I" [External ballistics. Part II], Printing house of the Artillery Engineering Academy, 501 p.

3. Modern Exterior Ballistics. The Launch and Flight Dynamics of Symmetric Projectiles / Robert L. McCoy. - Schiffer Publishing, 2004. - 328 p.

4. Lewtas Ian, Mcalister Rachael, Wallis Adam, Woodley Clive, Cullis Ian (2016) "The ballistic performance of the bombard Mons Meg”, Defence Technology, p. 59-68. https://doi.org/10.1016/j.dt.2015.12.001

5. Ke Liang, Zheng Huang and Jing-min Zhang. (2017) Optimal design of the aerodynamic parameters for a supersonic two-dimensional guided artillery projectile, Defence Technology, №13, pp. 206-211. http://dx.doi.org/10.1016/j.dt.2017.05.003

6. Sahoo S., Laha M.K. (2014) Coefficient of Drag and Trajectory Simulation of $130 \mathrm{~mm}$ Supersonic Artillery Shell with Recovery Plug or Fuze, Defence Science Journal, 64 (6), p. 502-508 DOI: 10.14429/dsj.64.8110

7. Bo Zhang, Shushan Wang, Mengyu Cao, Yuxin Xu. (2014) Impacts of Deflection Nose on Ballistic Trajectory Control Law. Mathematical Problems in Engineering, Vol. 2014, Article ID 984840, http://dx.doi.org/10.1155/2014/984840

8. Stepanov,E. and Vavilov S. (1997) The main problem of external ballistics, Computers Math. Application, V. 33(5), pp. 95-101. https://doi.org/10.1016/S0898-1221(97)00022-9

9. Cech,V, Jedlicka, L. and Jevicky, J. (2014) Problem of the reference height of the projectile trajectory as a reduced meteo-ballistic weighting factor, Defence Technology, №10, pp. 131-140. http://dx.doi.org/10.1016/j.dt.2014.06.002

10. Tkachuk, P.P., Velychko, L.D. and Horchynskiy, I.V. (2018), "Vplyv vitru na zovnishnu balistyku kuli vypeshchenoi z SVD" [Wind influence on the exterior ballistics of the bullet movement released from SVD], Military Technical Collection, V. 19, pp. 43-49. DOI: https://doi.org/10.33577/2312-4458.19.2018.43-49

11. Shooting tables for the plain and mountain conditions of a 100-mm T-12 (MT-12) anti-tank gun. ed. the third. - M.: Military Publishing House, 1988. - 88 p.

12. Landau, L.D., Lifshitz E.M., (1986), "Teoreticheskaya fizika: Uchebnoye posobiye: Dlya vuzov. V 10 t. T.VI. Gidrodinamika. - 3-ye izd., pererab" [Theoretical Physics: Textbook: For higher education institutions. In 10 vols. V. VI. Hydrodynamics. - 3rd ed., Remaking], M.: Nauka. Gl. red. fiz.-mat. lit., 736 p. 